\title{
Community Engagement and Service Learning
}

Ronald W. Welch

EDI 2015 Kiawah Island

14 April 2015 


\section{Introduction}

- Dean of Engineering, The Citadel

- West Point, University of Texas at Tyler, The Citadel

- What worked

- Resources needed 


\section{What is Service Learning?}

Community Need Served

1. Bona fide need is documented

2. Agency is effective at meeting the need

3. Volunteers have the skills to meet the need with agency guidance/training

4. Impact on those served can be (and is) documented
Student Learning takes Place

1. Student prepares for service by learning about agency and people served

2. Student fully participates in service experience

3. Impact on students who serve is documented through reflective, qualitative, and quantitative methods

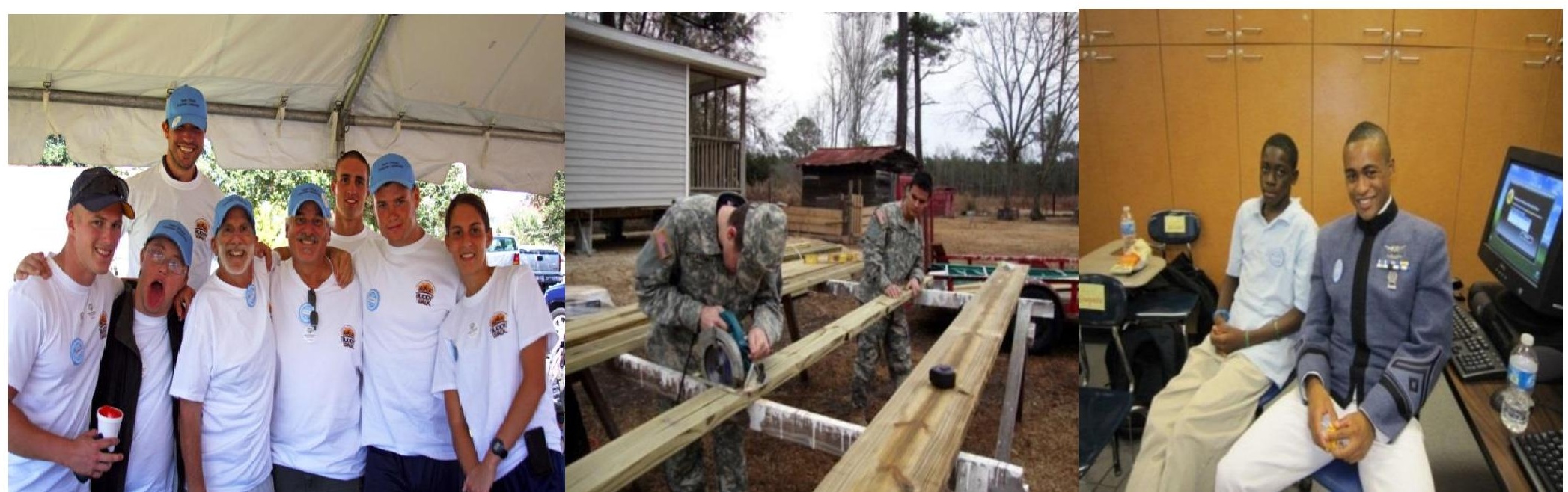




\section{Community Service Learning at West Point}

- Tasked with building an experiential independent study project for every Civil Engineering Student

- Only had 1-2 per year; needed 16-20 per year

- Developed projects in 3 areas:

- UG Research

- Competition

- Community Service 


\section{Service Projects at West Point}

- FBI Training Facility

- Reconfiguration of training facilities for Homeland Security

- Infrastructure Assessment Tools for Department of Defense

- Jones Beach Water Tower Analysis

- Kosciusko's Garden Redesign

- Picatinney Arsenal Homeland Security Training Faculty

- Low-water Crossing Design along California-Mexico Border

- Bloomington IL Homeland Security Training Facility

- Roof Support System Design for PV Energy System

- Popolopen Creek Footbridge Design

- West Point Lower Post Recreation Complex Design

- Walden Humane Society Renovation

- Constitution Island Timber Bridge design/construction Motor Pool Timber Bridge design/construction CTHE 


\section{Service Projects at West Point}

- ...Not counting Capstone projects

- Multiple groups competing for opportunity

- ASCE Chapter freshmen-junior enlisted to support

- Key: Developing Global Community Leaders

- ABET assessment

- All projects required the same outputs

- Report

- Presentation to Stakeholders

- Presentation on Projects Day

- Life-Long Learning 


\section{Leadership and Service}
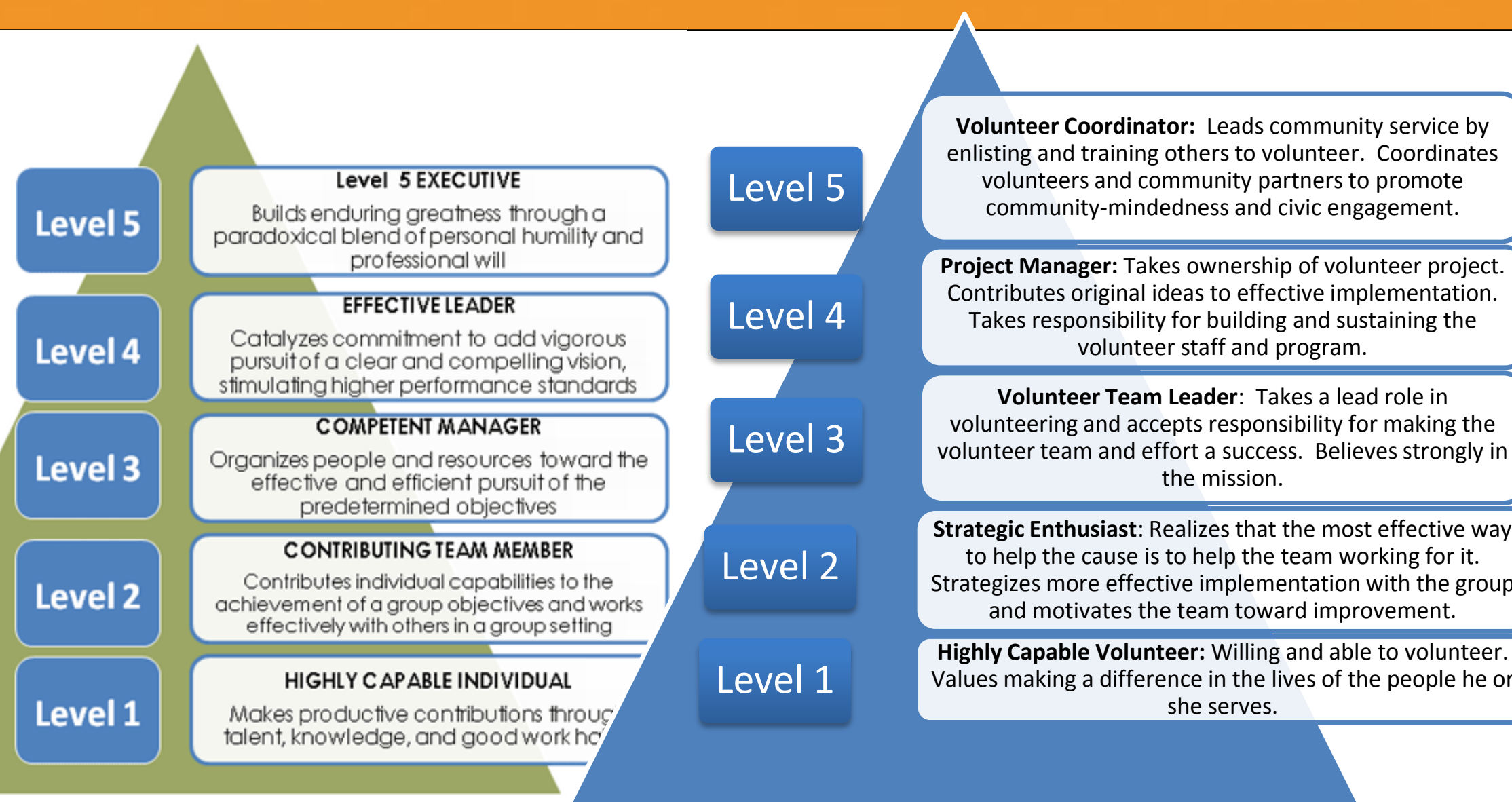

Volunteer Coordinator: Leads community service by enlisting and training others to volunteer. Coordinates volunteers and community partners to promote community-mindedness and civic engagement.

Project Manager: Takes ownership of volunteer project. Contributes original ideas to effective implementation. Takes responsibility for building and sustaining the volunteer staff and program.

Volunteer Team Leader: Takes a lead role in Level 3 volunteering and accepts responsibility for making the volunteer team and effort a success. Believes strongly in the mission.

Level 2

Level 1
Strategic Enthusiast: Realizes that the most effective way to help the cause is to help the team working for it.

Strategizes more effective implementation with the group and motivates the team toward improvement.

Highly Capable Volunteer: Willing and able to volunteer. Values making a difference in the lives of the people he or she serves. 


\section{New CE Program at UT Tyler}

- Same focus - developing global community leaders

- New program...so competition projects as part of ASCE Student Club focus

- Community Service projects within capstone design

- Designed New Engineering Building

- Redesign dangerous traffic intersection/add School welcome center

- Repurpose land for multi-purpose athletic fields for university and community use

- Redesign main administrative building to relocate all student services to a centralized location

- Design New College of Pharmacy building

- Goal was eventually independent study projects for all...resources limited...\$ and people 


\section{The Citadel's Service Learning and Civic Engagement Program is celebrating Six YEARS years of "Learning by Serving"}

a) Cadets complete Four Year Leadership Developmental Model including increasing engagement in service learning; Student leaders increasingly drive the development and implementation of new programs

b) Community Partners collaborate in program development, training, accountability, assessment, workshops, and scholarly evaluation

a) Faculty Fellows create and document impact of service learning on those serving and those served

b) SC Campus Compact AmeriCorps VISTAs, graduate students, and Krause Center for Leadership and Ethics. Staff administer curricular and co-curricular SL\&.EE programs

a) Summer SUCCEED as Leaders program and AmeriCorps-VISTA Summer Associates focus on prevention of learning loss and inspiring healthy psychosocial changes in youth who live in poverty 


\section{The Citadel}

- All Freshmen participate in a service project

- All sophomores lead freshmen in a partner requested service project

- All sophomores must develop and lead a service project (leadership lab)

- A large number of juniors and seniors continue in service projects

- Carnegie classified program 


\section{dical Center}

- 9/11 Day of Service

- Heroism Day

- English 101 assignment

- Veteran's Day

- Weekly Rotations (ER, Chemotherapy, Prosthetics)

- Psychology Interns (Mental Health Ward)

- Graduate Student oral Histories

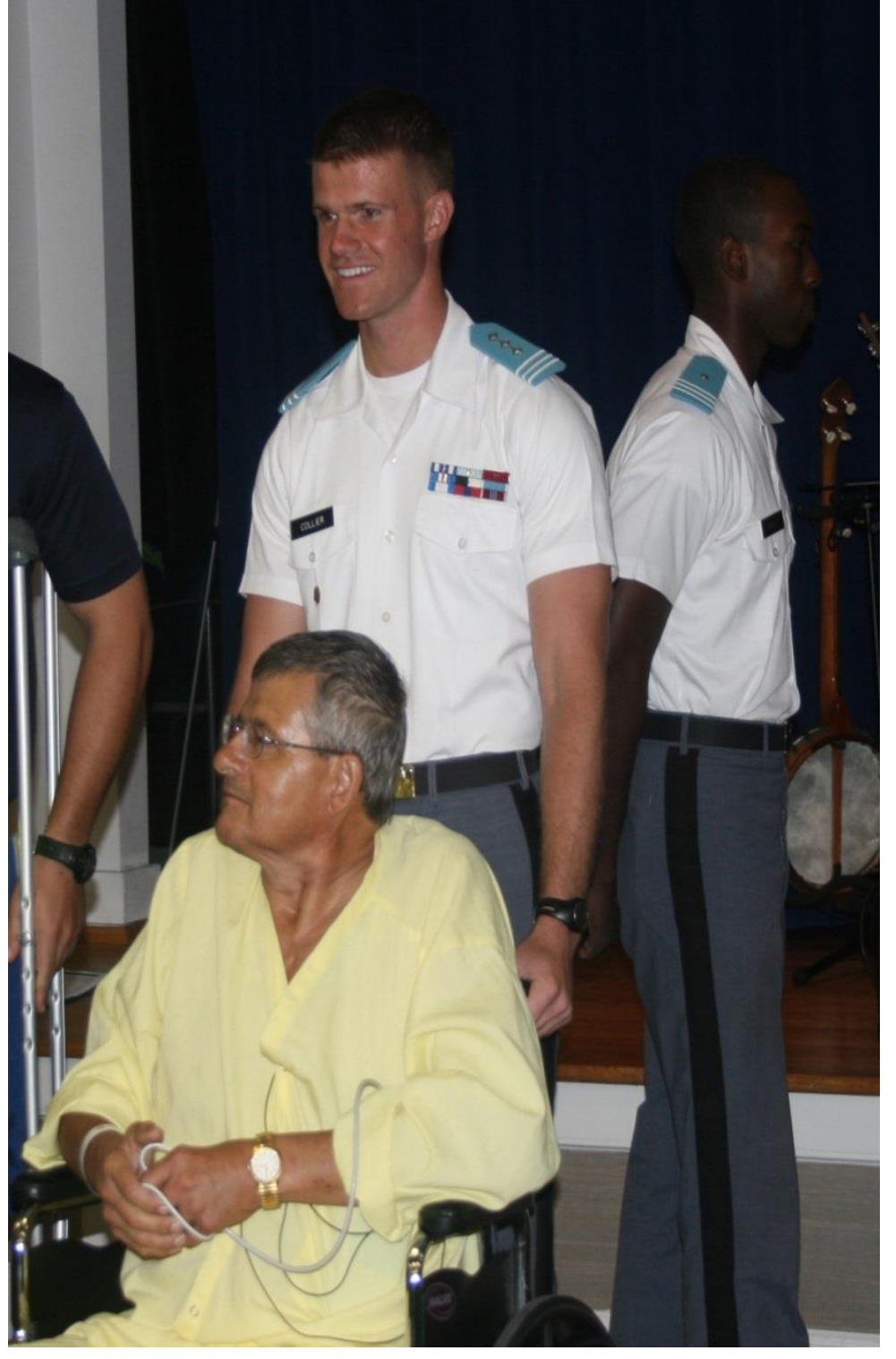




\section{Issues in Assessing Impact}

- Output vs. Impact

- What can we EXPECT to accomplish with the amount of intervention we offer?

- Qualitative vs. Quantitative

- Cost-effectiveness: What is measurable \& Grand plans vs. actual completion

- Who will collect \& summarize the data so they can inform our practice?

- Program Evaluation vs. Research

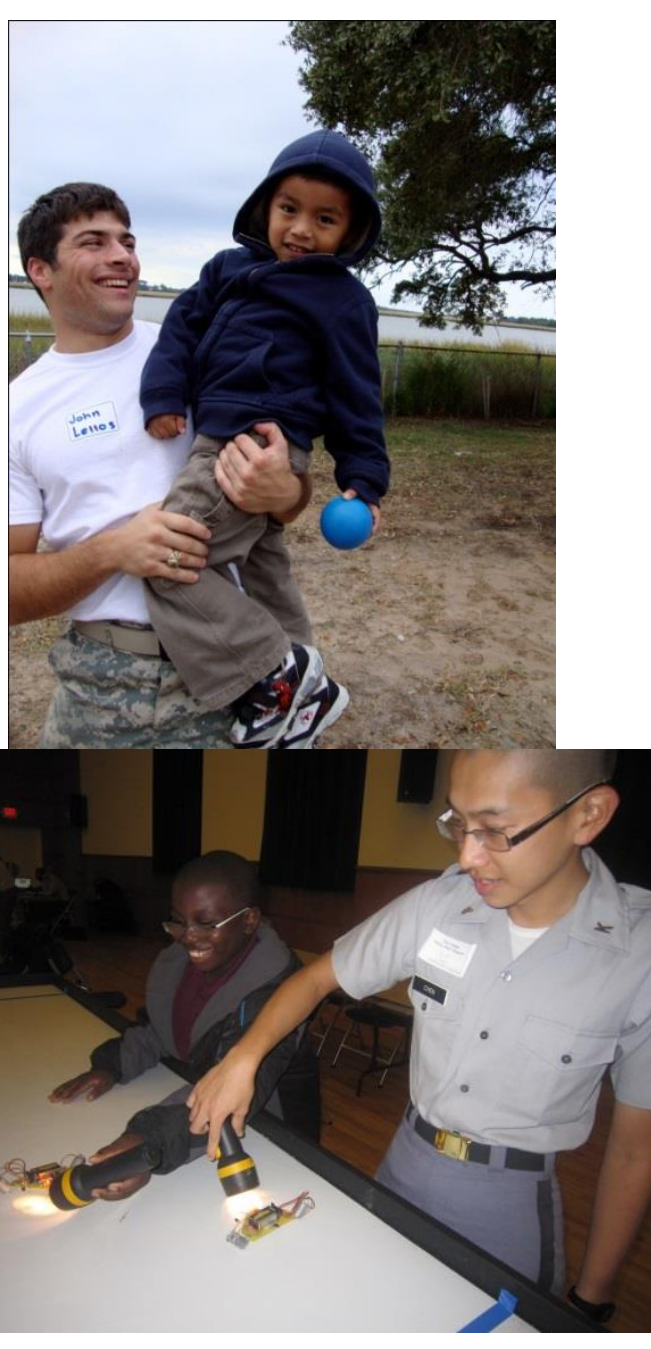




\section{Companies Benefit}

\section{HR executive view of volunteering within organization}

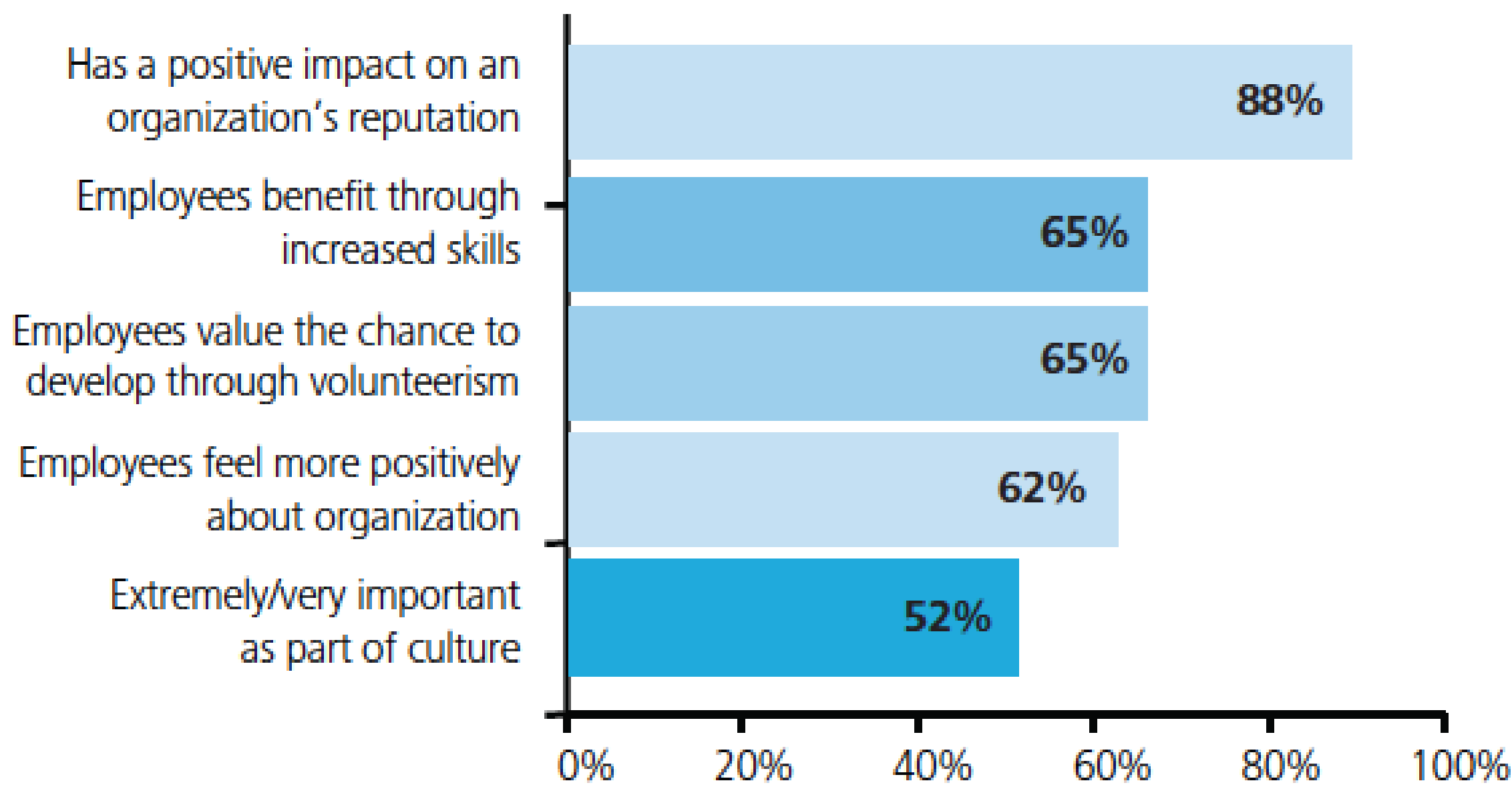

Year:

Deloitte Volunteer IMPACT Survey, 2013 


\section{Companies Benefit}

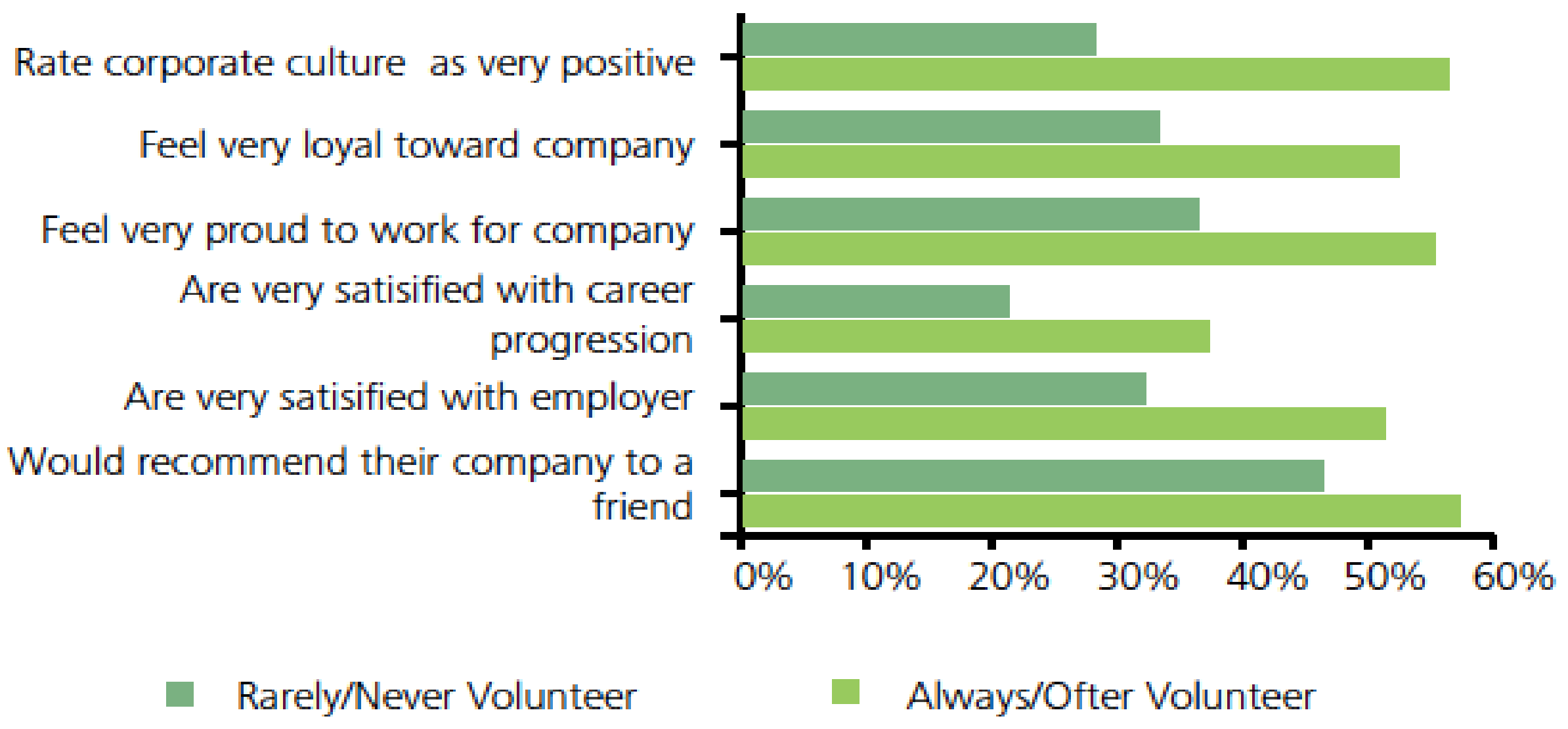

Figure 1. Millennials who frequently volunteer indicate higher levels of engagement than those who rarely or never volunteer. Year:

Deloitte Volunteer IMPACT Survey, 2011 


\section{Employers Benefit}

TIME MANAGEMENT SKILLS
STRONGER RELATIONSHIPS WITH COLLEAGUES

VOLUNTEERING BUILDS...
PEOPLE AND

TEAMWORK SKILLS

\section{(1)}
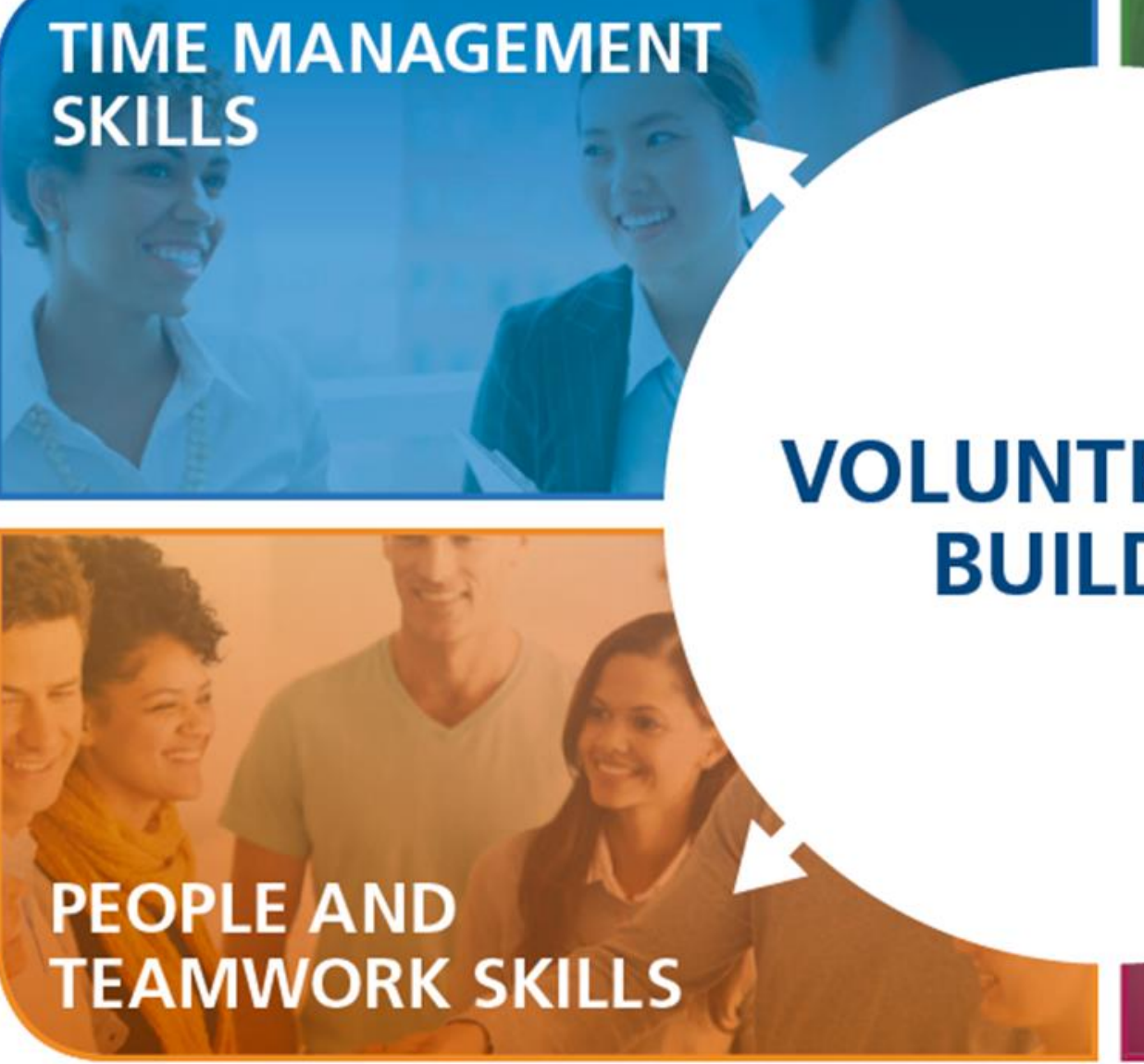

Volunteers Benefft

Source: UnitedHealthGroup 


\section{Job Seekers Benefit}

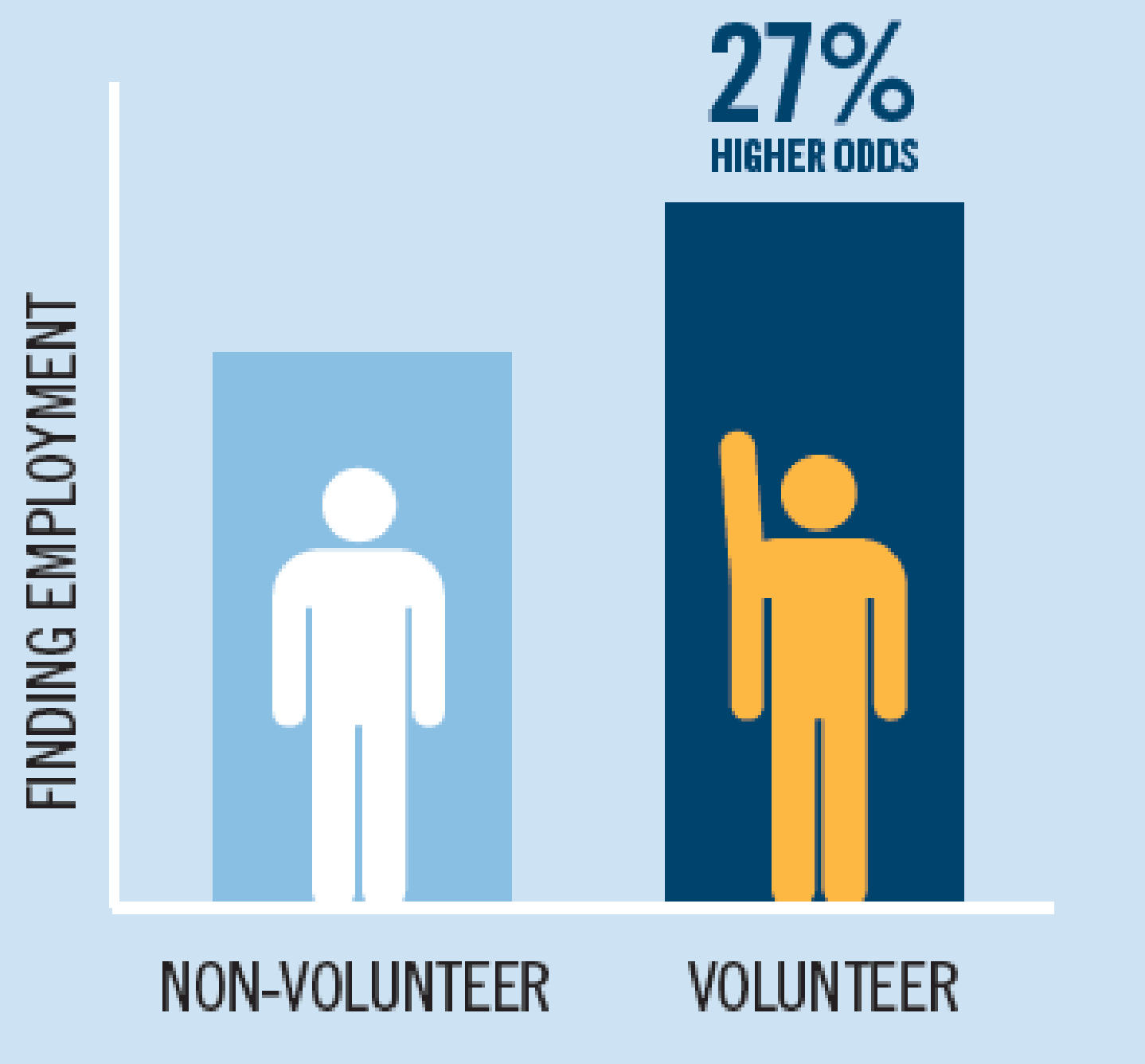

Source: Corporation for National \& Community Service, 2012 


\section{Job Seekers Benefit}

HR executive hiring decision-making process

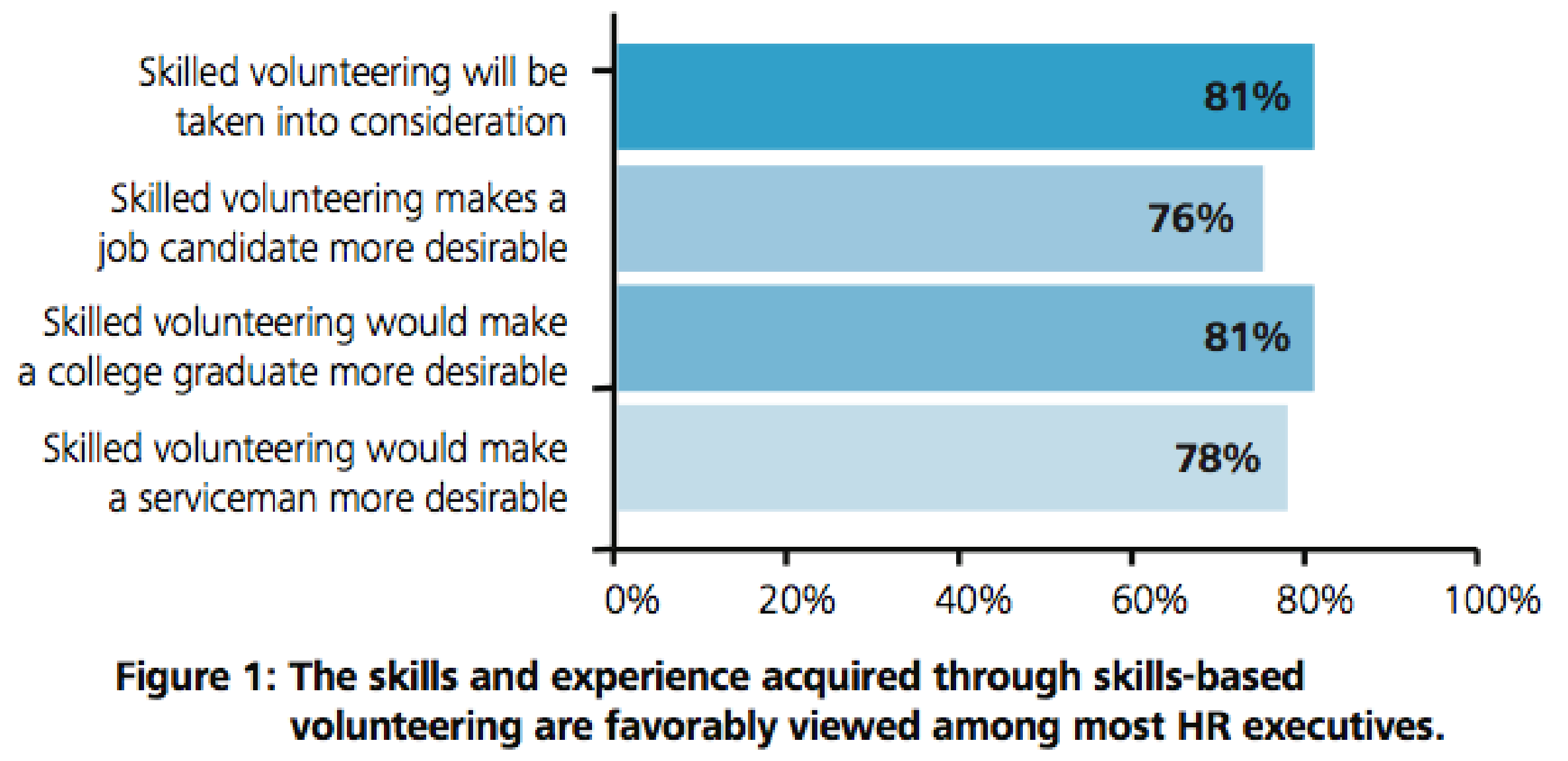

Year:

Deloitte Volunteer IMPACT Survey, 2013 


\section{The Citadel}

- Engineering juniors and seniors requesting service projects within club activities and capstone

- CE Capstones last two years:

- Wave Dissipation System

- Catholic Church Renovation

- Some of the EE Capstones the last two years:

- e-Porpoise:Electric Propelled Overboard Recovery Platform Offshore Intelligent Safety Equipment

- RRAID: Rapid Response Armor Impact Detection

- SmartPour

- Home Power Monitoring System

- G-Cap: Concussion Sensing Football Helmet

- Vehicle Parking Notification System

- The Door Security Check Robot

- Reducing Accidental Firearm Injuries with an RFID Firearm Safety System (RFSS)

- Intelligent Pill Cap System for Enhancing Prescription Adherence

- Intelligent Pharmaceutical Dispenser

- The Cipher, an Encryption Device for Android Phones using the Data Encryption Standard

- Spectrum Analyzer

$\longrightarrow$ THE 


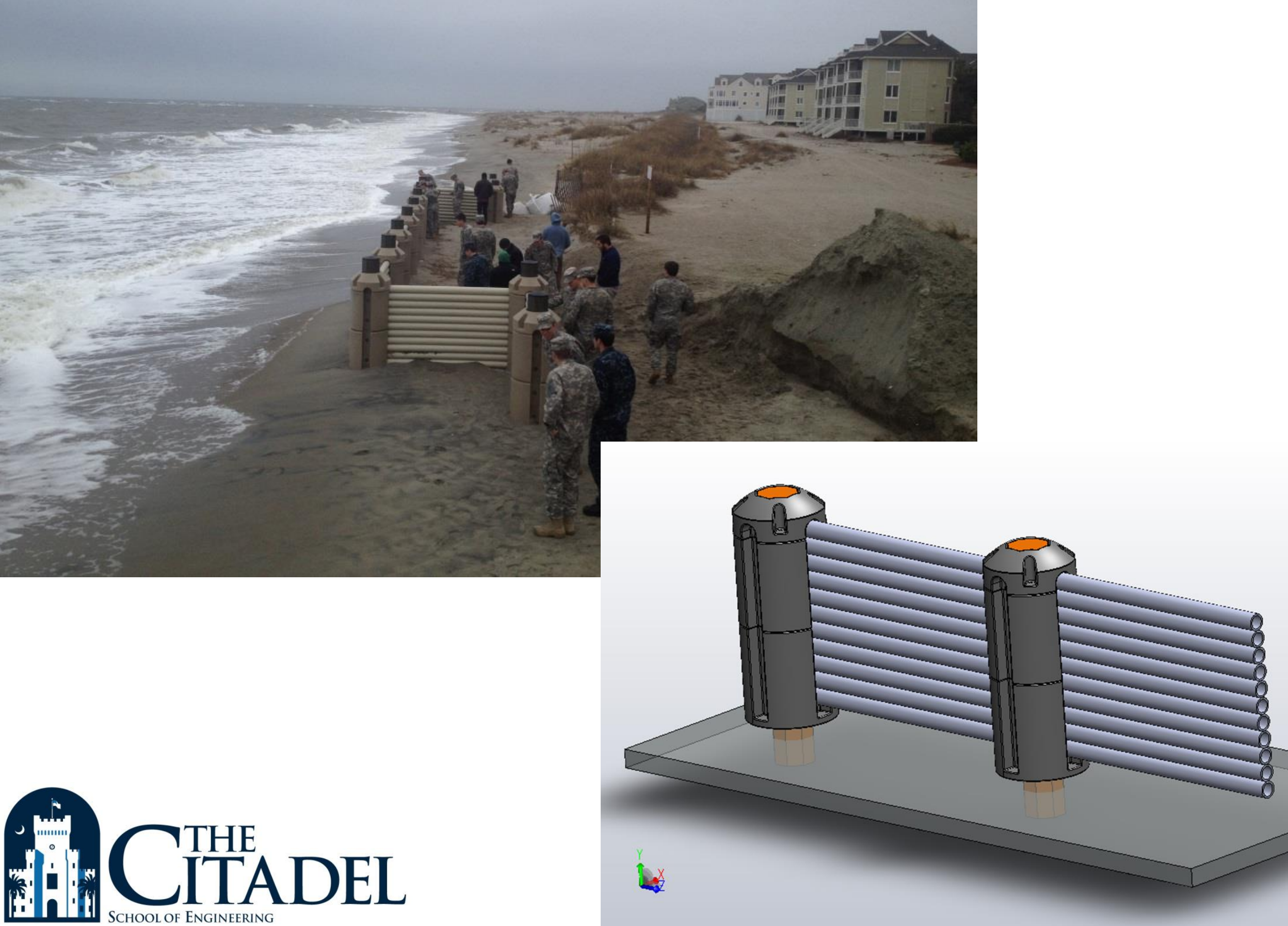




\section{Resources}

- Director (50\% faculty, $50 \%$ admin)

- 2 Graduate Students (half time)

- 2 Full-time AmeriCorps Vistas

- Infrastructure support - Krause Center for Leadership and Ethics (admin, event planning, assessment fundraising)

- Data entry and research covered by faculty research grants and/or donor funds

- \$12,500: Faculty Fellows

- $\$ 25,000$ (donor) for leadership day (food, T-shirts, school intervention supplies)

- $\$ 25,000$ throughout the year (bling, books, food for events)

- $\$ 8,000$ to bring community partners and campus constituencies together four times a year

- $\$ 12,000: 6-8$ Summer SUCCEED stipends

- Tap AmeriCorps Summer Associate program: 4 students for summer service

- Project advisors

- Key

- Administrator who can link partners and students

- Collect essential data (hours, products, impact surveys, etc.)

- No intervention without an assessment plan (IRB approved research)

- Some community service partners need the impact data to influence boards/donors

- Some partners have no funds to complete the required plans and designs THE 